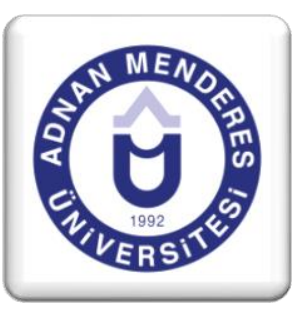

\title{
Kent Bilgi Sistemi ve Yerel Yönetimler Kocaeli Büyükşehir Belediyesi Örneği ${ }^{1}$
}

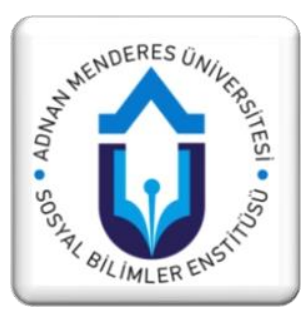

\section{ÖZET}

Günümüzde nüfusun büyük bir kısmının kentlerde yaşadığ1 ve her geçen günde arttığı göz önüne alındığında, yerel yönetimler giderek çeşitlenen ve karmaşık hale gelen kentsel sorunlarla karşılaşmaktadır. Kente ve kentliye ait verilerin toplanması, depolanması ve gerektiğinde kullanılmasına olanak sağlayan kent bilgi sistemleri etkin ve verimli çözümler üretme noktasında yerel yönetimler için önemli bir bilgi kaynağı oluşturmaktadır. 5393 Belediye Kanunu ve 5216 sayılı Büyükşehir Belediye Kanunu'nda belediyelerin görev ve sorumlulukları arasında gösterilen kent bilgi sistemleri konunun merkezi yönetim düzeyinde de ele alındığını göstermektedir. Çalışma coğrafi bilgi sistemleri ve onun kent yönetimi için tasarlanmış modeli olan kent bilgi sistemlerinin, uygulamada yerel yönetimler açısından sağladığı faydaların ve karşılaşılan sorunların incelenmesi amacıyla oluşturulmuştur. Araştırmada nitel araştırma yöntemlerinden yarı yapılandırılmış mülakat tekniği kullanılmıştır. Kocaeli Büyükşehir Belediyesi ve bünyesinde bulunan birimlerde çalışan personellerle yapılan mülakatlar yoluyla verilere ulaşılmıştır.

Anahtar Kelimeler: Coğrafi Bilgi Sistemi, Kent Bilgi sistemi, Yerel yönetimler

\section{City Information System and Local Governments: Case of Kocaeli Metropolitan Municipality}

\begin{abstract}
Given that a large part of the population now lives in cities and increases day by day, local governments are faced with increasingly diverse and complex urban problems. City information systems that enable the collection, storage and use of data belonging to citizen and urban areas are an important source of information for local governments at the point of producing effective and efficient solutions. The 5393 Municipality Law and 5216 Metropolitan Municipality Law show that the city information systems, which are among the duties and responsibilities of the municipalities, are also considered at the central government level. The study is conducted in order to examine the geographical information systems and city information systems, which are designed for city, and in order to examine the benefits and problems in terms of local administrations in practice. Semi structured interview technique was used as qualitative research methods in the research. Kocaeli Metropolitan Municipality and the units within the organization have been reached by means of interviews conducted with staff working.
\end{abstract}

KeyWords: Geographic İnformation System, City İnformation System, LocalGovernments

\footnotetext{
${ }^{1} \mathrm{Bu}$ çalışma, 29.07.2017 tarihli EUREFE'17 uluslar arası kongresinde sözlü olarak sunulmuştur.

${ }^{2}$ Arş. Gör. Maksud Emre Mülazımoğlu, Kocaeli Üniversitesi.
} 


\section{Giriş}

Kentlerin hızla gelişmesi ile hizmet alanın büyümesi bunun paralelinde insanların artan talepleri, yerel yönetimlerin görev ve sorumluluklarının artarak daha karmaşık bir hal almasına neden olmaktadır. Hangi hizmetlerin ne zaman yapılacağı ile ilgili kararları alma aşamasında, kente ve kentliye ait bilgilerin toplanması ve bunların saklanarak, tekrar kullanılmak üzere hazır hale getirilmesine duyulan ihtiyacın giderek artması sonucunda sağlıklı ve sürdürülebilir kentsel gelişme için bilgi teknolojilerinin sunduğu imkanlardan yararlanmak hem merkezi hem de yerel yönetimler tarafindan kuşkusuz bir gereklilik halini almıştır.

Konumsal (kente ait) ve konumsal olmayan (kentliye ait) verilerin bir arada toplanıp, aralarında ilişkiler kurularak analiz edilmesine imkan sağlayan kent bilgi sistemi (KBS) gerek merkezi gerekse yerel yönetimlerin çok yönlü hizmet sağlama gereksinimleri karşısında, uygun çözümler sunabilmektedir. Ülkemizde 5216 sayılı Büyükşehir Belediyesi ve 5393 sayılı Belediye Kanunları ile coğrafi ve kent bilgi sistemlerinin kurulması yerel yönetimlerin görevleri arasında sayılarak, konu özelinde hukuki zorunluluklar getirilmiştir. Ayrıca Çevre ve Şehircilik Bakanlığı'nın kurularak, Coğrafi Bilgi Sistemleri Genel Müdürlüğü'nün tesis edilmesi konunun ulusal düzeye taşınarak, merkezi yönetim tarafından ele alındığını göstermektedir.

$\mathrm{Bu}$ çalışma, ülkemizin yönetim alanına girmeye başlayan kent bilgi sistemlerinin yerel yönetimler alanındaki uygulamasının araştırılarak sağladığı faydaların ve karşılaşılan sorunların neler olduğunun tespitini yapmak amacıyla oluşturulmuştur. Bu amaçla özellikle kent bilgi sistemi uygulamasına geçişte ülkemizde pilot bölge olan ve çalışmalarını tamamlayan Kocaeli Büyükşehir Belediyesi Kent Bilgi Sistemi uygulaması ayrıntılı bir şekilde açıklanmıştır. Büyükşehir Belediye bünyesindeki daire başkanlıklarında çalışan personeller ile gerçekleştirilen yarı yapılandırılmış mülakatlar yoluyla bilgilere ulaşılmış olup kent bilgi sisteminin uygulamada sağladı faydalara ve karşılaşılan sorunlara yer verilmiştir.

Çalışmanın birinci bölümünde kent bilgi sistemi tanıtılmış, ikinci ve üçüncü bölümlerde ise ülkemizde merkezi ve yerel düzeyde coğrafi ve kent bilgi sistemleri için yapılan çalışmalara ve mevcut duruma dair bilgilere yer verilmiştir. Son bölümde ise Kocaeli Büyükşehir Belediyesi uygulaması incelenerek sonuçlar hakkında bilgiler verilmiştir.

\section{Kent Bilgi Sistemi Nedir ?}

Kent bilgi sisteminin daha iyi anlaşılabilmesi ve tanımının yapılabilmesi için veri, bilgi ve bilgi sistemi kavramlarının açıklanması gerekmektedir. Veri, gözlem ve deneye dayalı araştırmanın sonuçları olup (TDK) bilginin hammaddesi ve temsil biçimidir (Yomralığlu, 2000: 35).

Bilgi ise kişinin kurallardan yararlanarak veriye yönelttiği anlam, insan aklının erişebileceği olgu, gerçek ve ilkelerin tümü olarak tanımlanabilir (TDK) (Yomralıŏlu, 2000: 35).

Mevcut veri ve bilgileri bir sistem içerisinde toplayan, depolayan ve işleyip değerlendirerek etkili olarak kullanılabilmelerini sağlayan sistemlere ise bilgi sistemleri denilmektedir (Eser, 2011: 6) 
Günümüzde artan ve karmaşıklaşan problemleri çözmek amaciyla bilgi sistemlerine olan ihtiyaç giderek artmaktadır. Bilgi sistemlerine katmış olduğu hız, etkinlik ve daha doğru işlem gücü sayesinde ise bilgisayar teknolojilerinden faydalanmak kaçınılmaz bir hale gelmektedir.

Bilgisayar teknolojisi ile merkezi bir bilgisayar sistemi etrafında birçok kullanıcının bilgiyi aynı veya değişik zaman ve mekanlarda paylaşmaları mümkün olacağından bilginin önemi ve etkinliği artmaktadır (Tecim, 1999: 3).

Bilgi sistemleri, konumsal bilgi sistemleri ve konumsal olmayan bilgi sistemleri olmak üzere iki kısımda incelenebilir. Konumsal bilgi sistemleri, herhangi bir konuma bağlı olan harita bilgileri, imar planı bilgisi, çevre, bahçe, park, düzenleme ile ilgili proje bilgileri, çevre kirlilik harita ve proje bilgileri olarak örneklendirilebilir. Konumsal olmayan bilgi sistemleri ise personel bilgileri, yasa, yürütme ve yönetim bilgileri, arazi kullanım bilgileri, tarihi ve turistik yeşil doku alanları, sit ve koruma alanı karar bilgileri gibi sözel bilgileri ihtiva etmektedir (Baz, 1999: 32) (Altay, 2007: 5-7).

Oldukça kompleks ve fazla olan grafik bilgilerin (konumsal) sözel bilgiler (konumsal olmayan) ile coğrafi bir tabanda ilişkilendirilmelerini sağlayan ve bu yolla çeşitli analizlerin ve sorgulamaların yapılmasını mümkün kılan bir takım özel sistemler geliştirilmiştir.

Coğrafi Bilgi Sitemi olarak isimlendirilen bu sistem, yeryüzüne ait bilgileri belirli bir amaca yönelik olarak toplayan, bilgisayar ortamında depolayan, kontrol eden, sorgulamaya, analiz etmeye ve görüntülemeye olanak sağlayan teknik aletler bütünü olarak tanımlanabilir (Banger, 2011:124).

Coğrafi bilgi sistemlerinin kentsel düzeydeki uygulaması olan kent bilgi sistemi ise kent ve kentliye ait bilgilerin belirli yöntemlerle toplanması uygun yazılım ve donanımlar kullanıp bir veri tabanına aktarılması, veriler arasındaki ilişkilerin kurulması, yönetilmesi ve doğru sorgulamalar oluşturup analizlerin yapılarak kentin her türlü ekonomik, sosyal, kültürel, idari ve diğer hizmetlerinin en iyi şekilde gerçekleştirilmesini sağlamak amacı ile kurulan sistemlerdir (Erdoğan vd, 2005: 2) (Okçu vd, 2013: 5). Bu noktada gözden kaçırılmaması gereken husus kent bilgi sisteminin, coğrafi bilgi sisteminin imkanları kullanılarak, yerel yönetimler ölçeğinde hazırlanan bir sistem olduğudur.

Kent bilgi sisteminin asıl gücü ise bu noktada karşımıza çıkmaktadır. Yerel yönetim birimleri, merkezi idare kuruluşları ve valilik ile birlikte kent ve kentlinin ihtiyaçlarını karşılayan diğer kuruluşların sahip olduğu verilerin tek bir bilgi sisteminde toplanması, aralarında ilişkiler kurularak analizler yapılması ve bunların depolanması daha önce mümkün değildi. Bu sayede yaşanmakta olan hızlı kentleşme ve buna paralel olarak artan ve karmaşık hale gelen kentsel sorunlar karşısında KBS, yerel yönetimler başta olmak üzere kent idaresinden sorumlu diğer aktörlerin tek bir platform altında daha rahat koordine olmalarını sağlayarak, alınacak kararlarda katılım unsurunu da ön plana çıkarmaktadır. Ayrıca yerel kamu politikası yapım sürecinde bir karar-destek sistemi olarak daha doğru kararların verilebilmesini sağlaması, sistemin yönetime yardımcı bir araç hüviyetinde olduğunu göstermektedir.

Kent bilgi sisteminin yerel yönetimlerin halihazırda kaynaklarını etkin bir şekilde değerlendirmesine imkan vermesi, mekana ilişkin bilgileri saklayıp yönetmesi, kentin alt yapısının (doğalgaz, elektrik, içme suyu, telefon) kontrol altında tutulması, hizmetlerin yerine getirilmesinde kurumlar arasındaki ilişkileri sağlaması, trafik yoğunluğu olan 
bölgelerin tespiti yapılarak çözümler geliştirilebilmesi, çevre kirliliğinin etkileyeceği alanların etki dereceleri ile birlikte göstermesi, deprem, savaş, sel gibi acil durumlarda belirli bölgelerin en kısa sürede boşaltılması ile ilgili simülasyonları kurgulaması gibi gelecek hakkında daha doğru tahminler yapmaya elverişli bir sistem olması nedeniyle günümüzde kamu kurum ve kuruluşlarında kullanımı yaygınlaşmaktadır (Yomralığlu vd, 2002: 2) (Okçu vd, 2013: 6-7).

Ayrıca KBS gibi bilgi sistemlerindeki teknolojik gelişmelerin klasik kamu yönetimi anlayışını ifade eden güçlü merkeziyetçi yapıyı, yavaş işleyen bürokratik mekanizmayı, şeffaflıktan uzak ve kamu politikası oluşturma sürecinde diğer aktörlerin katılımına kapalı olan yapıyı olumlu yönde dönüştüreceğini de ifade edebiliriz (Okcu vd, 2013: 4) (Pektaş, 2009: 246).

Bir yerel yönetim biriminde kent bilgi sisteminin kurulması, işlerlik kazandırılması ve sürdürülebilir olması ise birden çok etmene bağlı bulunmaktadır. Özellikle veri toplama aşaması kent bilgi sistemi oluşturmada en uzun ve pahalı olan kısımdır.(veri toplama ve önemi) Kağıt haritalar, uydu görüntüleri, hava fotoğrafları gibi KBS veri kanallarının çokluğu ve dağınık oluşu yoğun emek ve yüksek maliyeti beraberinde getirmektedir (Dicle, 2011: 60-63).

Sistemin, yerel yöneticilerin yapacakları iş ve işlemlerde en doğru kararı alabilmeleri bir başka deyişle kamu yararını tesis edebilmeleri, verilerin güncel olmasını gerektirmektedir. Verilerin güncelliğinin sağlanması ise KBS'ye bağlı tüm paydaşların gerekli hassasiyeti göstermesine ve koordine bir şekilde çalışmasına bağlıdır.

Özellikle yerel yönetimlerin yönetim yapısı içinde yöneticilerin yeniliğe ve değişime karşı çekinceli bir tavır sergilemesi, sistemin kurulum aşamasında yüksek maliyetler gerektirmesi, yerel yönetimlerin sahip olduğu personelin KBS kullanımı konusunda yeterliliğe sahip olmaması veya yeterliliğe sahip personellerin devir hızının yüksek olması uygulamada en sık karşılaşılan sorunlardır.

\section{Türkiye’de Merkezi Hükümet Düzeyinde Kbs Çalışmaları}

CBS ve KBS uygulamalarının en önemli getirilerinden birisi merkezi ve yerel düzeydeki kamu yönetimi teşkilatları arasında veri paylaşımına imkan vererek bütünleşmeyi sağlamasıdır.

Ülkemizde kamu yönetimi teşkilatlarının, CBS ve KBS uygulamaları için ihtiyaç duydukları veriler merkezi hükümet kuruluşları, valilikler ve belediyelerden sağlanmaktadır (Durduran ve Geymen, 2008:6). Mevcut verilerin ve kullanıcı ihtiyaçlarının doğru bir şekilde belirlenmesi için tüm aktörlerin koordineli bir işbölümü çerçevesinde çalışması ve tüm bilgilerin CBS ve KBS uygulamalarına entegre edilmesi gerekmektedir (Dicle, 2011: 82-83). $\mathrm{Bu}$ nedenlerden dolayı ulusal bir veritabanı oluşturmak ve ülke çapında standartlar geliştirmek için merkezi yönetim düzeyinde bir takım çalışmalar yapılmıştır. 


\subsection{Tapu Ve Kadastro Bilgi Sistemi (TAKBİS)}

Ülke genelinde mülkiyet bilgilerinin bilgisayar ortamına aktarılması ve her türlü sorgulamanın yapılabilmesi amacıyla 2001 yılında TAKBİS uygulamasına geçilmiştir (Tapu ve Kadastro Genel Müdürlügü̈, https://www.tkgm.gov.tr/tr/sayfa/tapu-ve-kadastro-bilgisistemi-takbis / 11.12.2017).

CBS ve KBS / Arazi Bilgi Sistemleri mantığı çerçevesinde analiz edilerek, problemlerin belirlenmesi, çözüm yollarının bulunması, tapu ve kadastro hizmetlerinin bu yolla standart ve elektronik olarak yerine getirilmesi, yerel yönetimler, ulaşım, orman, tarım, enerji gibi birçok disiplin ve sektöre arazi bilgi sistemi mantığında doğru, güvenilir ve güncel bilgiler sunulması amacıyla oluşturulmuştur (Yalçın vd, 2009: 2-3). Yapılacak hizmetler Tapu ve Kadastro Genel Müdürlügü̈nün (Tapu ve Kadastro Genel Müdürlüğü, https://www.tkgm.gov.tr/tr/sayfa/tapu-ve-kadastro-bilgi-sistemi-takbis /11.12.2017) sorumluluğu altındadır. Bununla birlikte kamu kurumları TAKBİS üzerinden veri-alış verişi yaparak; belediyelerce kentsel alan planlaması, yatırımcı kuruluşlarca kamulaştırma planlarının hazırlanması, hazine arazilerinin değerlendirilmesi gibi hizmetleri gerçekleştirecektir (Tapu ve Kadastro Genel Müdürlüğü, https://www.tkgm.gov.tr/tr/sayfa/tapu-ve-kadastro-bilgi-sistemi-takbis / 11.12.2017).

\subsection{Türkiye Ulusal Coğrafi Bilgi Sistemi (TUCBS)}

E-Dönüşüm Türkiye Projesi kapsamında TUCBS kurma çalışmaları 2003 yılında başlamıştır. Ulusal bazda kurulacak CBS uygulamaları için temel verinin mülkiyet (mekan) verileri olması nedeniyle ana aktör Tapu ve Kadastro Genel Müdürlügü’dür. E-Dönüşüm Türkiye Kısa Dönem Eylem Planı'nın 47 numaralı eylem planında mevcut durum analizi yapılmış, eylem 36'da TUCBS için olası uygulama modellerinin üzerinde durulmuştur. Ayrıca eylem planı 75 ile birlikte Ulusal Coğrafi Veri Altyapısı Kurulması çalışmaları yapılmıştır (Avcı vd, 2014: 3-4).

\subsection{Coğrafi Bilgi Sistemleri Genel Müdürlüğü (CBSGM)}

2011 yılında Çevre ve Şehircilik Bakanlığı oluşturulması ile birlikte bakanlık teşkilatı içinde CBSGM tesis edilmiştir. Genel müdürlüğün KBS'nin standartlarını belirleyerek yaygın bir şekilde oluşturulması için gerekli düzenlemeleri yapması, etkin ve verimli bir şekilde kullanılmasını teşvik etmesi ve eş güdümü sağlaması öne çıkan görevleridir. Bu sayede yerel yönetimlerin gerçekleştireceği KBS çalışmalarında standart ve içerikler belirlenerek ülke genelinde bütünleşme sağlanmıştır.

\subsection{Kent Bilgi Sistemleri Standartlarının Belirlenmesi Projesi (KBİSS)}

Coğrafi Bilgi Sistemleri Genel Müdürlüğü tarafından gerçekleştirilen KBİSS projesinin amacı mevcut mevzuatın taranarak, yerel yönetimlerde kent bilgi sistemine konu olabilecek konum/mekan bazlı herhangi bir veri/bilgi içerip içermediğini tespit etmek olarak belirtilmiştir. Konu ile ilgili 113 mevzuat dökümüne ulaşılmıştır. Etkin bir KBS için; dağınık olan ve çeşitlilik gösteren mevcut yasal hükümlerin iyileştirilmesi gereğinin altı çizilerek, 
"Coğrafi Bilgi Sistemi Yasası" ve buna bağl1 "Kent Bilgi Sistemleri Yönetmeliği" düzenlenmesine ihtiyaç olduğu sonucuna ulaşılmıştır (Coğrafi Bilgi Sistemleri Genel Müdürlüğ̈̈, 2012: 103).

\section{Türkiye'de Yerel Yönetimlerin Kent Bilgi Sistemine Geçmesinin Nedenleri Ve Mevcut Durum}

Ülkemizde yerel yönetimlerin CBS ve KBS uygulamalarına geçişinde en önemli etken olarak yasal düzenlemeleri gösterebiliriz. Konu özelinde 5393 sayılı Belediye Kanunu'nun "belediyenin görev ve sorumluluklarının" açıklandığı 14. Maddesinde "Belediye, mahalli müşterek nitelikte olmak şartıyla; a) coğrafi ve kent bilgi sistemleri; yapar ve yaptırır." hükmü yer almaktadır. Aynı şekilde 5216 sayılı Büyükşehir Belediye Kanunu'nun 7. Maddesinde coğrafî ve kent bilgi sistemlerini kurmak, Büyükşehir, ilçe ve ilk kademe belediyelerinin görev ve sorumlulukları arasında sayılmaktadır. Bensghir ve Akay (2006), yerel yönetimlerin KBS ile birlikte CBS kurma zorunluluğunu, yerel yönetimlerin sadece kent bilgi sistemleri olarak değil CBS'nin diğer açılımlarını da (afet bilgi sistemi, karar destek sistemleri) görmelerini sağlayacak olumlu bir girişim olarak değerlendirmektedir.

Hukuki zorunluluk dışında, bugün dünyada olduğu gibi ülkemizde de görülen kentlere doğru nüfus artışı ve beraberinde ortaya çıkan kentsel sorunlar karşısında, kente ve kentliye ait bilgilerin, bir araya getirilerek bilgisayar ortamında depolanıp güncelliğinin korunması ve işlemlerin bu bilgisayarlar aracılığı ile takip ve organize edilmesi, yerel yönetimlerin hizmetleri verimli ve etkin bir şekilde yerine getirebilmelerinde başat bir faktör olarak karşımıza çıkmaktadır (Eser, 2011: 16) (Pektaş, 2009: 245).

Bilgi teknolojilerinin hızla gelişimi toplumların, bilgi toplumuna evrilmesini de beraberinde getirmektedir. Bilgi toplumu bireylerinin ise istedikleri zaman sorgulamalar yaparak bilgiye ulaşma talebi, yerel yönetimlerinde bilgi paylaşımı yapabilecek sistemleri kurmalarını zorunlu hale getirmektedir. Ayrıca kurumların kendi ihtiyaçlarını da karşılamak için de bilgi sistemlerinin kullanımına ihtiyaç vardır.Yapılacak iş ve işlemlerde suistimalleri en aza indirip kamu ve vatandaşın çıkarını koruması, belediye gelirlerinin takibinin yapılabilmesi, yatırımların planlanması, uygulanması ve işletilmesinde en verimli ve doğru uygulamaları yapması (İnce, 1999: 40) gibi özellikleri de KBS'nin yerel yönetimlerce tercih edilme nedenleri arasında gösterilebilir.

Buraya kadar ülkemizdeki yerel yönetimlerin KBS uygulamasına geçmesinde etkili olan faktörleri özetle şu şekilde açıklayabiliriz:

1) Hukuki zorunluluklar,

2) KBS'nin yerel yönetimlerin hem kurum içi ihtiyaçlarında hem de halka karşı görev ve sorumluklarını yerine getirmede yardımcı bir yönetim aracı olması,

3) Bilgi toplumuna geçişinin başlaması ile birlikte toplumdaki bireylerin bilgiye daha rahat ulaşabilmesi ve bunun sonucunda değişen davranış kalıpları karşısında kamu kurumlarının bu dönüşüme ayak uydurabilmesinin sağlanması.

Türkiye'de yerel yönetimlerin KBS kurulumları hangi düzeydedir? Bu soruya İç İşleri Bakanlığı, Mahalli İdareler Genel Müdürlüğü'nün Mart 2011 y1lında gerçekleştirdiği "EDevlet (Yerel) Uygulamaları Anketi Raporlaması" isimli çalışma ile cevap verebiliriz. EDevlet(Yerel) uygulamaları anketi, toplam 2.950 belediyeden 2.666'sının katılımıyla gerçekleştirilmiştir. Ankete katılan belediyelerin 114 tanesinde KBS çalışmalarının 
tamamlandığı, 2.552 belediyede ise çalışmaların tamamlanmadığı sonucuna ulaşılmıştır. Rakamlar grafik halinde, bölgeler arası karşılaştırmalarla birlikte verilmiştir.

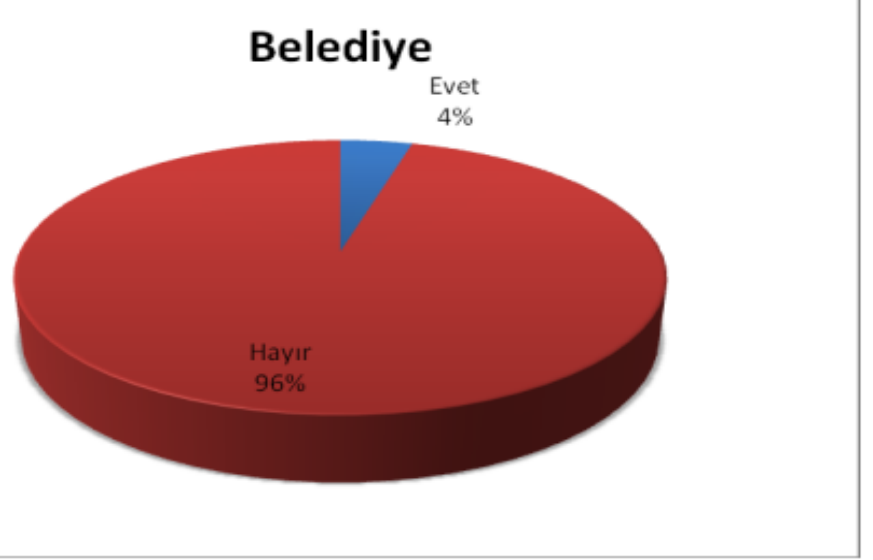

Şekil 1: Türkiye'de yerel yönetimlerin KBS kullanım düzeyi

Kaynak: E-Devlet (Yerel) Uygulamaları Anketi Raporlaması

Bölgeler arasındaki duruma baktığımızda Marmara Bölgesi’nin diğer bölgeler ile kıyaslandığında KBS çalışmalarında daha başarılı olduğunu ve onu İç Anadolu ve Ege Bölgeleri'nin takip ettiğini görebiliriz. Rakamlar ve grafik aşağıdaki gibidir:

*Marmara Bölgesinde 46 evet, 212 hayır. * * Iç Anadolu Bölgesinde 24 evet, 616 hayır.

*Ege Bölgesinde 15 evet, 487 hayır. $\quad$ *Karadeniz Bölgesinde 9 evet, 457 hayır.

*Doğu Anadolu Bölgesi 6 evet, 247 hayır. $\quad$ *Akdeniz Bölgesinde 9 evet, 382 hayır.

*Güneydoğu Anadolu Bölgesinde 5 evet, 151 hayır.

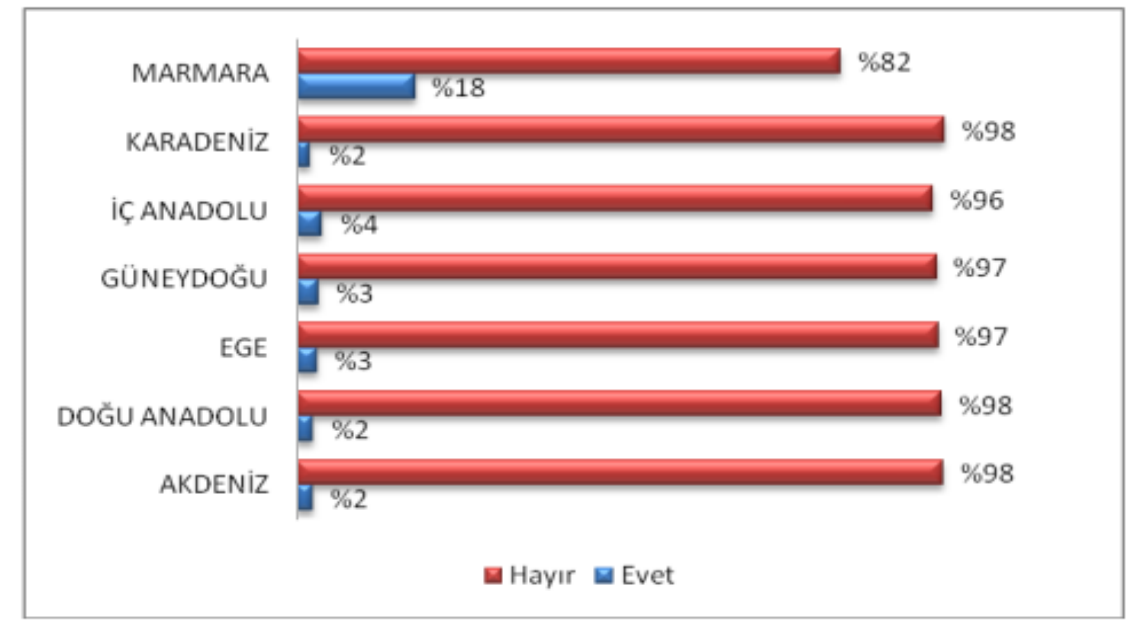

Şekil 2: Coğrafi bölgeler temelinde KBS kullanım oranları

Kaynak: E-Devlet (Yerel) Uygulamaları Anketi Raporlaması 
Yukarıda da belirtildiği üzere Mart 2011 yılına ait veriler, ülkemizdeki yerel yönetimlerin sadece 114 tanesinde (\%4) KBS kurulumunun gerçekleştirildiğini göstermektedir. Her ne kadar sayının az olduğu dikkati çekse de birinci bölümde açıkladığımız KBS kurulumuna etki eden faktörler göz önüne alındığında, sürecin meşakkatli olduğu unutulmamalı ve değerlendirmeler buna göre yapılmalıdır. Ayrıca ulusal düzeyde bütüncül bir yapı tesis edilebilmesi için merkezi yönetim düzeyinde coğrafi bilgi sistemi çalışmalarının yapılması nedeniyle süre gelen zamanda mevcut sonuçların olumlu yönde gelişim gösterebileceğini düşünmemiz yanlış olmayacaktır.

\section{Kent Bilgi Sistemi Uygulaması Kocaeli Büyükşehir Belediyesi Örneği}

2004 yılında İzmit Büyükşehir Belediyesi'nden Kocaeli Büyükşehir Belediyesi'ne geçiş yapılarak, görev sınırları tüm il sınırı haline gelen Kocaeli'nde, bilgi sistemlerine duyulan bu ihtiyaç giderek artmıştır. Kocaeli Büyükşsehir Belediyesi öncülüğünde kent bilgi sisteminin kurulması çalışmalarına coğrafi bilgi sistemleri şube müdürlüğü 2007 yılında başlamış olup, halen diğer daire başkanlıklarının da sisteme entegre edilmesi için gereken çalışmalar devam etmektedir.

Kocaeli Kent Bilgi Sistemi dış kaynaklama yoluyla sağlanan donanım ve yazılımı dışında tamamen kurum içi personel tarafından tasarlanmıştır. Model, tüm ili kapsayacak düzeyde düşünülerek tek bir kent bilgi sistemin kurulması amaçlanmıştır. (Aydın, 2014: s.75-76)

Kocaeli modelinde sistem merkezi bir platform üzerine inşa edilmiştir. Ana server, büyükşehir belediye bünyesinde kurulmuş olup tüm veriler burada toparlanmıştır. Diğer belediyeler, su idaresi, gaz şirketleri, Telekom, valilik vb. ilgili proje ortakları network sistemi üzerinden merkeze bağlanabilmekte, kendi verilerini belirlenmiş standartlara uygun bir şekilde sisteme girip güncellemelerini yapabilmektedir. Bunun dışında her kurum kendilerini ilgilendiren konularda sistemden yararlanarak çeşitli bilgilere ulaşabilecek ve böylelikle kurumlar arası koordinasyon sağlanabilecektir. (Aydın, 2014: s.76-77) (Demirci vd, 2009:s.1-5)

Kocaeli Kent Bilgi Sistemi'nin veri tabanını; Nüfus ve Vatandaşlık İşleri Genel Müdürlüğü, valilik, ilçe belediyeleri, belediye birimleri, Tapu ve Kadastro Genel Müdürlüğü, İSU, IZGAZ vd. kurmuş olduğu alt yapı bilgi sistemlerinden alınan veriler ile oluşturulmuştur.

Kocaeli Kent Bilgi Sistemi, Coğrafi Bilgi Sistemleri Şube Müdürlügünün sorumluluğundadır. Şubede bir şehir planlamacısı, jeofizik mühendisi, bilgisayar programı teknikeri, bilgisayar mühendisi, jeodizi ve fotografi mühendisi, iki tane harita mühendisi olmak üzere yedi personel çalışmaktadır. Coğrafi Bilgi Sistemi Şube Müdürlüğünün görevleri ise şunlardır: (Kocaeli Büyükşehir Belediyesi, 2017: s.5-6)

- Kocaeli genelinde CBS ve benzeri sistemleri kurmak, kurdurmak ve yürütmek.

- Alt yap1 koordinasyon merkezinin CBS'ye dair kamu kurum kuruluşları ile özel kuruluşlardan isteyeceği bilgi ve belgelerin standartlarını belirlemek.

- CBS ye yönelik uygulama ve mobil uygulama programlarını hazırlamak.

- Teknolojik gelişmeleri ve mevzuat değişikliklerini takip ederek, CBS uygun veri üretim standartlarını oluşturmak, uygulatmak ve güncel tutmak.

- CBS sunucularında depolanan verilerin müdürlük dışındaki kurumlar ve birimler ile paylaşmak için gerekli bürokratik işlemleri gerçekleştirmek. 
- KBB adına nüfus, bağımsız bölüm, yapı belgeleri, kadastro, tapu, imar planı vb. verileri yetkili kurumlardan web servisleri aracılı̆̆g ile temin edebilmek.

- CBS veri tabanı sunucularında bulunan verilerin / servislerin KBB Meclisi'nce ilgili senesi için onaylanmış Gelir Tarifesindeki satış bedellerine göre kişi ve kurumlara satışını gerçekleştirmek.

- Müdürlük kapsamında yapılacak danışmanlık ve hizmet ihaleleri ile ilgili tüm evrakları hazırlayıp ihale birimine sunmak.

- Müdürlüğün alanına giren konular ile ilgili bilgi vermek ve teknik incelemelerde bulunmak için yurtiçi ve yurtdışı platformlara katılmak.

Kocaeli Büyükşehir Belediyesi'nde Coğrafi Bilgi Sistemi’ni kullanan birimler ve bu birimlerin faaliyetlerini yürütürken ilişkide bulunduğu birimlerin en önemlileri; İmar ve Şehircilik Dairesi Başkanlığı, Emlak İstimlak Dairesi Başkanlığı, Fen İşleri Dairesi Başkanlığı, Ulaşım Dairesi Başkanlığg ve ilçe belediyeleridir.

Kocaeli Büyükşehir Belediyesi Kent Bilgi Sistemi, Adres Bilgi Sistemi temelinde yedi modülden oluşmaktadır. (Demirci vd 2009: s.2-4) (Aydın, 2014: s.81-85) Bunlar; altyapı, acil durum, çevre, sosyo-kültürel, imar, ulaşım ve üst yapı modülleridir. Bu modülleri şu şekilde açıklayabiliriz.

Adres Bilgi Sistemi: Diğer modüllerin üstüne kurulduğu bir platformdur ve iki ana içerikte hazırlanmıştır. Birincisi; şehir rehberi uygulaması, üzerinde işaretlenen noktaya ait "Adres Bilgileri", "Kadastro Bilgileri", "Yap1 Bilgileri", "Vergi Dairesi Bilgileri", "1/1000 Plan Bilgileri", "Nüfus Bilgileri" detayları sorgulanabilirken, İSU, SEDAŞ ve Türk Telekom A.Ş.'nin yürüttüğü kazı çalışmaları, trafik bilgisi ve nöbetçi eczaneler ile ilgili bilgilendirme hizmetleri de sunulmaktadir.

Altyapı Modülü: Kocaeli’nde bulunan altyapı kurumlarının grafik verilerinin sözel veriler ile birlikte tek bir platformda toplandığ 1 sistemdir. Bu sayede online olarak kazı ruhsatı verilebilmekte, altyapı hatlarının sorgulanabilmesi ile birlikte oluşabilecek tehlikeler önlenebilmektedir. İSU, İZGAZ, SEDAŞ ve AYKOME gibi kurumlar sisteme katkı sağlayan kullanıc1lardır.

Acil Durum Modülü; Sistem, Kocaeli'nin deprem, sanayi kaynaklı vakalar, sel, salgın hastalıklar gibi bir takım riskleri içermesi nedeniyle oluşturulmuştur. Her türlü risk anında, bölge bulunan insanların tahliye edilebilmesi için, il sınırlarındaki yollar hakkında detaylı bilgiler toplanarak en kısa süre içinde yardım ekiplerinin olay yerine ulaşımı sağlanabilmektedir. Salgın hastalıkların takibinin yapılabilmesi ve erken müdahalenin gerçekleştirilebilmesi için il sağlık müdürlügü ile veri alış-verişi yapılmaktadır.

Çevre Modülü: Çevre kirliliği ile ilgili verilerin sisteme aktarılmasıyla karbon ve kükürt oranları takip edilebilmekte, eşik değerleri aşıldığında ise uyarı mekanizmaları devreye girmektedir. Coğrafi Bilgi Sistemleri Şube Müdürlüğü’nde yapılan görüşme sonucunda şu bilgiler edinilmiştir: "Hali hazırda Çevre Koruma Dairesi ile birlikte Çevresel Gürültü Direktifi Projesi’ni yürütmekteyiz. Kentimizdeki sorunlu bölgelerin coğrafi olarak tespitini yaptık ve değerlendirmelerimizi sunduk. Çevre Koruma Dairesi şuan raporları incelemekte ve çıkan sonuçlara göre örneğin ses duvarı inşası gibi bir takım projeler yürütülmesi planlanmaktadır. Gelecek yılın sonunda proje detayları, Çevre Bakanlığı tarafından kamuoyu ile paylaşılacaktır." İfade edildiği üzere sistem sayesinde gürültü kirlilik analizleri yapılmakta ve gerekli önlemlerin alınması için çalışmalar devam etmektedir. 
Sosyo-Külttürel Modül; İl genelinde büyükşehir belediyesinin yaptığı yardımların sorgulanabilmesi için web arayüzü hazırlanmıştır. Bu sayede, yapılan yardımların takibi sağlanarak, suistimallerin önüne geçilerek vatandaşlar ile yakın ilişkiler kurulması amaçlanmaktadır.

İmar ve Taşınmazlar Modülü: Emlak ve İstimlak Dairesi'nce kurulan sistem Belediye’ye ait tüm taşınmazların kanunlara ve mevzuatlara göre kayıt edilmesi ve arşivlenmesini sağlamaktadır. Ayrıca belediyeye ait taşınmazların ihale yoluyla satışı, devri, tahsisi, kiralama, kamulaştırma ve ecri misil gibi süreç bazlı işlemlerin yürütülmesi ve sorgulanabilmesi gerçekleştirilmektedir.

Ulaşım Modülü: Kentte ulaşım ile ilgili bulunan tüm araç ve gerecin analizinin yapılması için kurulan sistemdir. Toplu Taşıma Dairesi Başkalığı'nca geliştirilen E-Komobil uygulaması ile insanlar otobüs ve vapur saatlerine, kendilerine en yakın noktada bulunan duraklara, bir yerden başka bir yere nasıl gidebilecekleri ile ilgili bilgiye, kent kart bakiyelerine ve kapalı güzergahlara kadar web üzerinden sorgulamalar yapabilmektedir.

Üstyapı Modülü: Kentte bulunan tüm üstyapı çalışmalarının takip edilebildiği bir sistemdir. Yeni yapılacak yol çalışmalarının özellikleri ile ilgi web ortamında bir arayüz hazırlanarak sorgulanabilir hale getirilmiştir.

\section{Araştırma Yöntemi}

Bu çalışma nitel araştırma yöntemlerinden yarı yapılandırılmış mülakat tekniği kullanılarak hazırlanmıştır. Yarı yapılandırılmış mülakat tekniğinin temel amacı bireyin bakış açısını anlayarak araştırılan konu hakkında bireyin deneyimleri, tutumları, düşünceleri, niyetleri, yorumları, zihinsel algıları ve tepkileri gibi gözlenemeyen bilgilere ulaşmaktır. (Sönmez vd, 2011:108). Önceden hazırlanmış görüşme protokolüne bağlı olarak mülakatların sürdürülmesi daha sistematik ve karşılaştırılabilir bilgiye ulaşılmasına imkan vermektedir (Yıldırım vd, 1999: 283).

Çalışma, kent bilgi sisteminin uygulamada yerel yönetimlere sağladığı faydaların ve karşılaşılan sorunların tespitini yapmak amacıyla tasarlanmıştır. Bu anlayış doğrultusunda Kocaeli Büyükşehir Belediyesi bünyesinde bulunan Bilgi İşlem Dairesi, Emlak ve İstimlak Dairesi, İmar ve Şehircilik Dairesi, Fen İşleri Dairesi, Ulaşım Dairesi Başkanlıkları'nda çalışan personellerle mülakatlar yapılmıştır.

Çalışmayı ilgi çekici kılan husus, daha önce yerel yönetim kuruluşlarında çalışan personellerin kent bilgi sistemine dair algı ve gözlemlerini araştıran bir çalışmanın olmamasıdır. Ancak bu durum aynı zamanda çalışmanın kısıtlarını da ortaya çıkarmaktadır. Kent bilgi sistemi hakkında her personelin bilgi ve ilgi seviyesinin farklı oluşu nedeniyle ulaşılan bulguların parçalı bir yapıda olması, kodlamanın daire başkanlıkları ismiyle yapılmasını zorunlu kılmıştır. 


\subsection{Bulgular}

\subsubsection{KBS Kullanımının Sağladığı Faydalar}

\subsubsection{Zaman ve İș Gücü’nden Tasarruf}

Sitemin en önemli faydası klasik yöntemlerle karşılaştırıldığında sunulan hizmetler noktasında zaman ve iş gücünden sağladığı tasarruftur. İ.Ş.D.B. ve E.İ.D.B. olarak kodlanan birimlerde gerçekleştirilen görüşmelerden " Bu sistemden önce örneğin belirlenen adreslere göre parsel tespiti yapma işlemi saatlerimi allyorken şimdi birçok işlemi dakikalar içinde halledebiliyorum". "Uzun süreç ve ortaklar içeren alım, satım, kiralama, kamulaştırma gibi işlemlerin tüm basamaklarının sisteme yüklenmesi sayesinde masa başında işlerimi yapabiliyorum. İş yükümü azaltmasının yanında psikolojik olarak da çalışanı rahatlatan bir durum. "şeklinde ulaşılan bulgular sistemin çalışan motivasyonu üzerinde de olumlu etkiye sahip olduğunu göstermektedir.

\subsubsection{Daha Doğru Kararların Verilmesi ve Hizmet Kalitesi’ni Arttırması}

Sistem sayesinde kente ve kentliye ait bilgilere sahip olan yerel yönetimlerin halkın ihtiyaçlarını daha iyi tespit eder hale gelmesi, sunulacak hizmetlerin de daha nitelikli olmasını sağlamaktadır. İ.Ş.D.B. olarak kodlanan birimden "Sistem ile birlikte parsellerin tapu alanı, malik bilgileri, bir projede kaç kişi olduğunu, ne kadarıyla uzlaştı̆̆ımızı tek bir tıkla görebiliyorum. İşimiz gereği daha önce yapılmış projelere ulaşmamız gerektiğinden sistem bize hiz kazandirtyor ve bu gibi bilgileri talep eden vatandaşlara daha iyi ve hizlı hizmet vermemi sağllyor". F.İ.D.B. olarak kodlanan birimden ise "yaptığım iş ve işlemlerde kendimi daha rahat hissediyorum çünkü doğru olduklarına inanıyorum." şeklindeki ifadeler kent bilgi sisteminin hizmet kalitesi ve daha doğru kararlar verilmesi üzerinde sahip olduğu olumlu etkiyi göstermektedir.

\subsubsection{Kurumsal Hafiza}

Kurumsal hafizayı örgütlerin bünyesindeki her türlü bilginin gerektiğinde ulaşılabilir ve kullanılabilir olması olarak açıklayabiliriz. Özellikle bir kamu kurumundan çeşitli nedenlerle ayrılan personelin beraberinde götürdüğü bilgi, işlerin aksamasına neden olmaktadır. Kent bilgi sistemi ile verilerin depolanıp arşivlenebilmesi, kamu kurumlarının kurumsal hafiza sorununu ortadan kaldırmaktadır. F.İ.D.B. olarak kodlanan birimden "Kamuda bir personel emekli olduğunda tüm bilgileri kendisi ile beraber götürür. Sistem sayesinde tüm bilgilerin depolanması ve geçmişe dönük yedeklerinin oluşturulması ile bu sorun ortadan kalktı". U.D.B. olarak kodlanan birimden ise "Bir projeden sorumlu kişi, o gün iş yerinde olmasa dahi başka biri sisteme giriş yapıp, gereken bilgilere rahatça ulaşabilir". ş̧eklinde elde edilen bulgular aynı zamanda sistem sayesinde iş sürekliliğinin de sağlandığını göstermektedir.

\subsubsection{Etkin Bir Hesap Verebilirlik Aracı}

E.İ.D.B. olarak kodlanan birimden elde edilen bulgular şu şekildedir. "Kamu İdarelerine Ait Taşınmazların Kaydına İlişkin Yönetmelik 2006 yılında son halini almıştır. Bu tarihten sonra Sayıştay müfettişlerince gerçekleştirilen denetimlerde usule uygun arşivimizin olmaması ve evrakları gerektiği şekilde toparlayamadı̆̆ımız için başarılı olamadık. 3. tenkiti almamak için bu sistemi kurduk ve denetime hazır hale geldik." "Devir, tahsis, trampa, kiralama ile 
ilgili bilgilerin sisteme yüklenmesi sayesinde vatandaşın bu konular hakkında bize sordukları soruları daha çabuk ve doğru bir şekilde cevaplayabiliyoruz".

Kent bilgi sisteminin, herkesin istediği bilgiye ulaşabilmesi anlamında şeffaflık ve bir işlemin önceden planlanan şekilde sonuçlandırılması için belirli standartlara bağlanması ve ortaya çıkan sonucun bu standartlara göre düzeltilmesi anlamında denetim (Eryılmaz vd, 2011: 24) ile yakından ilişkili olan hesap verebilirliğin sağlanması noktasında önemli bir kanal olduğunu göstermektedir.

\subsubsection{KBS Kullanımında Karşılaşılan Sorunlar}

\subsubsection{Donanımlı Personel Eksikliği}

Kocaeli Büyükşsehir Belediyesi’nde kent bilgi sisteminden sorumlu olan birim Coğrafi Bilgi Sistemleri Şube Müdürlüğü’dür. Sistemin kurulumu ve sürdürülebilirliği açısından önemli görevleri bulunan birimin, yeterli personele sahip olmaması bir takım sorunlara yol açmaktadır.

$\mathrm{Bu}$ sorunların en önemlisi, sistemin diğer daire başkanlıklarının görev ve sorumluklarına göre kurulumunun gerçekleştirilememesidir. E.İ.D.B. olarak kodlanan birimden "K.b.s. hali hazırda elimizdeki personel ile kurulamayacak bir sistem çünkü yazllım ve programlama yapabilecek personel özel sektörde daha iyi ücretlerle çalışabilmektedir. Bu yüzden hem piyasadan bu hizmetleri satın alarak hem de elimizdeki personellerin özverisi ile bu sistemi kurmayı başardık." şeklinde ulaşılan bulgular, bu alandaki personel devir hızına dikkat çekerek aynı zamanda mevcut personelin yeniliğe ve bireysel olarak gelişime açık olması gerektiğinin de altını çizmektedir.

\subsubsection{Verilerin Toplanması ve Güncelleme}

B.İ.D.B. olarak kodlanan birimden şu bilgilere ulaşılmıştır. "Tapu ve Kadastro Müdürlüklerinde ki paftaların üstünde bulunan grafik verilerin hatalı ölçüler vermesi (evrak şeklinde bulunan belgeler), bunların düzeltilmesi için gereken zamanı da düşündüğümüzde hemen gerçekleştirmemiz çok zor. Bu durum yapılacak işleri de aksatmaktadır." Bir Kent Bilgi Sistemi oluşturulurken en fazla zamana ihtiyaç duyulan ve en fazla masraf gerektiren aşama veri toplama aşamasıdır. Ayrıca sistemin kullanımında eldeki verilerin güncelliğinin korunması, sistemden en çok faydanın sağlanması noktasında başat bir faktördür. Geçerliliğini yitirmiş, kullanıma uygun olmayan veriler yerel yönetimlerin doğru kararlar alma noktasında olumsuz etkileyerek yerel halka etkin ve verimli hizmet sunumunun gerçekleştirilmesinin önünde engel teşkil etmektedir.

\subsubsection{Kurum Dışı Veri Paylaşımı ve Koordinasyon Sorunu}

Kent bilgi sisteminin veri tabanını oluşturan ve sistemin paydaşları olan kurumlarla, yerel yönetimlerin koordinasyon sorunu yaşaması, veri paylaşımında problemlere yol açmaktadır. İ.Ş.D.B.olarak kodlanan birimden "Bir bölgede meydana gelen yaygın bir hastalı̆̆ın tespiti bizim için önem arz eden bir konudur çünkü acil olarak dönüştürülmesi gerekir. Fakat bu durumdan haberdar olabilmemiz için sağlık bakanlı̆̆ının hasta bilgilerini bizimle paylaşması gerekirken bunu yapmamaktadır." şeklindeki ifadeler ile B.İ.D.B. olarak 
kodlanan birimden "Karşılaştığımız en büyük sorun insanların tapudaki bağımsız bölüm numarası ile taşınmazının iç kapı numarasının birbiriyle örtüşmemesidir. Bu nedenle insanlar yanlış yere dask yaptırıyor. Bu sorunu kendi imkanlarımızla aştık fakat Tapu Kadastro ve Nüfus ve Vatandaşlık Işsleri Genel Müdürlügü’nün kat irtifakı kurulurken bu sisteme entegre olmaması ve bizim verilerimizi de sağlıkl görmemesi nedeniyle problemler yaşamaktayız. "ulaşılan bulgular kent bilgi sisteminin kullanımında paydaşların takındığı tutum ve davranışların işlerin verimli bir şekilde yürütülmesi açısından önem arz ettiğini göstermektedir.

\section{Sonuc}

Kente ve kentliye ait mekansal ve mekansal olmayan tüm bilgilerin belirli yöntemlerle toplanıp, bir veri tabanına aktarılması, uygun yazılım ve donanım desteği ile birlikte toplanan bilgiler arasında ilişkiler kurulmasını sağlayan kent bilgi sistemi, coğrafi bilgi sistemlerinin kent bazındaki uygulamasıdır. Ülkemizde özelikle büyükşehir belediyesi yönetimine geçiş ile birlikte belediyelerin sorumlu oldukları coğrafi alan genişlerken bunun paralelinde görev ve sorumlulukları da artmıştır. Ayrıca kent yönetimi ile ilgili kararlar alıp, gerekli hizmetleri yapma noktasında yerel yönetimler ile birlikte ortak çalışan kamu ve özel kuruluşların varlığı da düşünüldüğünde, daha komplike bir yapı ortaya çıkmaktadır. $\mathrm{Bu}$ sebeplerden dolayı eski usul ve yöntemlerle gerekli iş ve işlemleri yerine getirmeye çalışan yönetim mekanizmalarının, çağımızın getirilerinden olan bilgi teknolojilerinden yararlanması kaçınılmaz hale gelmektedir. Bu noktada karşımıza yönetim için gerekli karardestek birimi olarak çıkan CBS ve KBS uygulamaları ülkemizde de giderek yaygınlık kazanmaktadır.

Coğrafi ve kent bilgi sistemi uygulamalarının sadece yerel yönetim ölçeğinde değil merkezi yönetim düzeyinde de ele alınması, kamu yönetimi örgütünün değişimi en az sorunla atlatması ve sürdürülebilirliği sağlaması açısından önemli bir husustur. Ülkemizde CBS ve KBS uygulamaları merkezi yönetim düzeyinde gerçekleştirilen TAKBIS; tapu kadastro işlemlerinin elektronik ortamda toplanması, TUCBS; ulusal bazda CBS uygulamasına geçiş, KBİSS; KBS ve CBS uygulamaları için gerek yasal altyapının araştırılması ve geliştirilmesi projeleri ile gerekli adımlar atılmaya çalışılmaktadır. Ayrıca Çevre ve Şehircilik Bakanlığı bünyesinde kurulan Coğrafi Bilgi Sistemleri Genel Müdürlüğü ile yerel ve merkezi düzeyde yapılacak çalışmaların koordinasyonun sağlanması amaçlanmıştır. Ayrıca 5216 sayılı Büyükşehir Belediyesi Kanunu ve 5393 sayılı Belediye Kanunu ile CBS ve KBS'nin kurulması yerel yönetimlerin görevleri arasında sayılarak, hukuki bir zorunlulukta getirilmiştir.

Öte taraftan sistemin kurulmasında karşılaşılan yüksek maliyetler, donanımlı personel eksikliği ve yeniliğe karşı gösterilen direnç nedeniyle KBS ve CBS uygulamalarına geçiş sürecinin uzadığını söyleyebiliriz.

Ülkemizde KBS uygulamasında pilot il olan Kocaeli, gerek sisteme entegre olması gerekse merkezi ve yerel düzeydeki ortakları ile yürüttüğü çalışmalar ile diğer yerel yönetim kuruluşlarına rehberlik etmektedir. KBS uygulamasının yerel yönetim kuruluşları açısından önem ve faydasının tespiti için Kocaeli Büyükşehir Belediyesi'nde gerçekleştirilen mülakatlar sonucunda bir takım sonuçlara ulaşılmıştır.

Tahmin edileceği üzere sistem, dosyalar halindeki bilgileri depolaması ve bir işlem için gerekli olan aşamaları elektronik ortama taşıması ile yapılacak iş ve işlemlerde zaman tasarrufu sağlayarak iş gücünü azaltmakta ve çalışan motivasyonunu olumlu yönde 
etkilemektedir. Ayrıca kentin ihtiyaçlarının doğru ve zamanında tespit edilip yapılacak hizmetlerde de en doğru kararın alınabilmesini sağlamaktadır. Sistemin getirdiği en büyük faydanın ise kamu kurumlarındaki tüm bilgi ve işlemleri depolaması ve yedeklemesi yoluyla kurumsal hafiza oluşturması ve kamu yönetiminde hesap verebilirliğin sağlanması açısından önemli bir araç olmasıdır.

Ancak sistemin kamu yönetimi örgütlerinde yer yer yeni kullanılmaya başladığı, eğitim süreçlerinin devam ettiği göz önüne alınırsa bir takım sorunlarla da karşılaşılmaktadır. Özellikle literatürde ve uygulamada sıkça karışımıza çıkan donanımlı ve konu ile ilgili personel esikliği, sistemin tatbikini olumsuz yönde etkilemektedir. KBS'den en çok faydanın alınabilmesi sistemin paydaşları arasında ortak çalışabilme anlayışının gelişmesine ve bu sayede veri paylaşımı ve güncelliğinin sağlanabilmesine bağlıdır. Bu noktada yapılan görüşmelerde karşılaşılan en büyük sorunun ise kurum dış1 veri paylaşımı konusunda aktörlerin gereken özeni göstermemesi ve verilerin güncelliğini kaybetmesidir. Bu sebeple kent ile ilgili yapılacak hizmetlerde aksama meydana gelmektedir.

Sonuç olarak KBS uygulamalarına geçiş yapan kurumların, hem kendi bünyesi içinde ki hem de çevresine karşı olan sorumlulukları yerine getirebilmesi, sistemin gerektirdiği iş yapma şekillerine uyum sağlanmasını zorunlu kılmaktadır. Bu sayede KBS'nin kent yöneticilerine olduğu kadar kentlilere de sağlayacağı fayda geliştirilip arttırabilir. 


\section{KAYNAKÇA}

ALTAY, Ö.(2007), Kent Bilgi Sistemi, Türkiye'deki Uygulamalar Ve Kayseri Örneği, (Yüksek Lisans Tezi), Selçuk Üniversitesi Jeodezi Ve Fotogrametri Anabilim Dalı, KONYA.

AVCI, C. ve DURDURAN, S. (2014), "Geçmişten Günümüze Kent Bilgi Sistemi Çalışmaları Ve Mevcut Durum" 5. Uzaktan Algılama-Cbs Sempozyumu (Uzal-Cbs 2014), İstanbul

AYDIN, İ. (2014), E-Devlet Uygulamalarında Coğrafi Bilgi Sisteminin Yeri: Kocaeli Büyükşehir Belediyesi Örneği, (Yüksek Lisans Tezi), Kocaeli Üniversitesi Sosyal Bilimler Enstitüsü, Kocaeli.

BANGER, G. (2011), Kent Bilgi Sisteminin Esasları. Ankara: Nobel Yayınevi

BAZ, İ. (1999), "Yerel yönetimler için kent bilgi sistemi tasarım1." Yerel Yönetimlerde Kent Bilgi Sistemi Uygulamaları Sempozyumu, KTÜ, Trabzon, 29-38

BENSGHIR, T. ve AKAY, A. (2006) "Bir kamu politika aracı olarak coğrafi bilgi sistemleri (CBS): Türkiye'de belediyelerin CBS uygulamalarının değerlendirilmesi." Çağdaş Yerel Yönetimler C.15, S.1: 31-46.

ERDOĞAN, C. CAN, M. ve ALKAN R. (2005), "Tokat Turhal İlçesi Coğrafi Bilgi Sistemi.", Harita ve Kadastro Mühendisleri Odası, Mühendislik Ölçmeleri STB Komisyonu 2. Mühendislik Ölçmeleri Sempozyumu İTÜ - İstanbul: 337-350

DEMIRCI, Y. ve TEKEL, M. (2009), "Kamu Yönetiminde Coğrafi Bilgi Sistemleri Uygulamaları: Kocaeli Örneği”, TMMOB Coğrafi Bilgi Sistemleri Kongresi, İzmir

DİCLE, M. (2011). Türk Kamu Yönetiminde Coğrafi Bilgi Sistemi (Cbs) Uygulamaları Ve Tr 83 Bölgesi Örneği, (Yüksek Lisans Tezi), Gaziosmanpaşa Üniversitesi SBE. Tokat.

DURDURAN, S.S. ve GEYMEN A. (2008), "Türkiye ede Afet Bilgi Sistemi Çalışmalarının Genel Bir Değerlendirmesi”, Erciyes Üniversitesi, 2. Uzaktan Algılama ve Coğrafi Bilgi Sistemleri Sempozyumu 13-15 Ekim 2008, Kayseri

ERYILMAZ, B. ve BİRİCiKOĞLU, H. (2011), "Kamu yönetiminde hesap verebilirlik ve etik." İş Ahlakı Dergisi c.4 s.7: 19-45.

ESER, Ü. (2011), Denizli Kent Bilgi Sistemi Tasarımı Ve Fayda/Maliyet Analizi, (Yüksek Lisans Tezi), Selçuk Üniversitesi FBE, Konya

İNCE, H. (1999), "Yerel Yönetimlerde Harita Bilgisine Olan İhtiyaçlar",Yerel Yönetimlerde Kent Bilgi Sistemi Uygulamaları Sempozyumu, KTÜ, Trabzon: 39-48

Kocaeli Büyükşehir Belediyesi Bilgi İşlem Dairesi Başkanlığı Görev ve Çalışma Yönetmeliği http://www.kocaeli.bel.tr/icerik/kocaeli-buyuksehir-belediyesibilgi-islem-dairesi-baskanligi-gorev-ve-calisma-yonetmeligi/2857/37487

(11.12.2017) 
OKÇU, M. vd, (2013) "Bir E-Devlet Uygulaması Olarak Kent Bilgi Sistemi: Mevcut Durum Ve Yeni Yönelimler." KAYSEM-8 Kuramdan Uygulamaya Yerel Yönetimler ve Kentsel Politikalar Bildiri Kitabi HATAY: 1-21

PEKTAŞ, K. (2009), "Coğrafi Ve Kent Bilgi Sistemi Uygulamaları Ve Afyonkarahisar İli Örneği." Afyon Kocatepe Üniversitesi, İ.İ.B.F. Dergisi C.11,S.1 : 241-260.

SÖNMEZ, V. ve ALACAPINAR, F. (2011). Örneklendirilmiş Bilimsel Araştırma Yöntemleri.

Ankara: Anı Yayıncılık.

Tapu ve Kadastro Genel Müdürlügü, https://www.tkgm.gov.tr/tr/sayfa/tapu-ve-kadastrobilgi-sistemi-takbis (11.12.2017)

TECiM, V. (1999), "Bilgi Teknolojilerinde Yeni Bir Gelişme: Coğrafi Bilgi Sistemleri Ve Bilgi Sistemleri Arasındaki Yeri." Dokuz Eylül Üniversitesi İktisadi ve İdari Bilimler Fakültesi Dergisi C14. S.1: 1-12

T.C. İçişleri Bakanlığı, Mahalli İdareler Genel Müdürlüğü. (2011), "E-Devlet (Yerel) Uygulamaları Anketi Raporlaması."

T.C. Çevre ve Şehircilik Bakanlığı, Coğrafi Bilgi Sistemleri Genel Müdürlüğü. (2012), "Kent Bilgi Sistemleri Standartlarının Belirlenmesi Projesi: İP-1 Mevzuat Analiz Raporu."

TDK, Güncel Türkçe Sözlük http://www.tdk.gov.tr/index.php?option=com_gts\&arama=gts\&guid=TDK.GTS.59 a2a0bbcfd585.04755118, (11.12.2017),

YALÇIN, G. vd (2009). "Harita, Tapu Ve Kadastro Hizmetlerinde Klasik Arşivden Sayısal Sunuma Doğru". TMMOB Harita ve Kadastro Mühendisleri Odas1 12. Türkiye Harita Bilimsel ve Teknik Kurultayı: Ankara

YILDIRIM, A. ve ŞİMŞEK, H. (1999). Sosyal Bilimlerde Nitel Araştırma Yöntemleri. Ankara: Seçkin Yayınevi.

YOMRALIOĞLU, T. ve ÇETE, M. "Kent Bilgi Sistemleri: Çağdaş Yerel Yönetim Aracı.", Jeodezi ve Fotogrametri Mühendisliği Bölümü, Karadeniz Teknik Üniversitesi, Trabzon (2002).

YOMRALIOĞLU, T. (2000), Coğrafi Bilgi Sistemleri Temel Kavramlar ve Uygulamalar, 1.Bask1, Akademi Kitapevi, Trabzon. 